\title{
Long-term impact of sagittal malalignment on hardware after posterior fixation of the thoracolumbar spine: a retrospective study
}

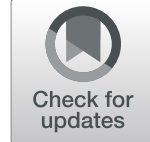

\author{
Mahmoud Elshamly ${ }^{1,2}$, Reinhard Windhager ${ }^{1,2}$, Stefan Toegel ${ }^{2,3}$ and Josef Georg Grohs ${ }^{1 *}$ (D)
}

\begin{abstract}
Background: The importance of sagittal alignment in healthy individuals and in reconstructive spinal surgery has been studied over the last 15 years. The aim of the present study was to assess the long-term effects of abnormal sagittal alignment on hardware after posterior thoracolumbar spinal fusion.

Methods: Patients who had undergone revision surgery (revision cohort, $n=34$ ) due to breakage of their implants were compared retrospectively with patients who had intact implants at the final follow-up investigation after a long posterior thoracolumbar and/or lumbar spinal fusion (control cohort, $n=22$ ). Clinical data and radiological parameters including the sagittal vertical axis (SVA), pelvic incidence (PI), lordosis gap (LG), pelvic tilt (PT), sacral slope (SS), lumbar lordosis (LL), thoracic kyphosis (TK), and the femoral obliquity angle (FOA) were assessed on fullspine lateral radiographs obtained in regular standing position. Data were analysed using descriptive statistics, parametric and non-parametric inferential statistics.

Results: Patients in the breakage group (female $n=21$, male $n=9$, mean age $60.9 \pm 15.6$ years) had a higher anterior shift of the C7 plumb line (SVA) ( $p=0.02)$, retroversion of the pelvis (PT) $(p<0.001)$, PI-LL mismatch (LG) $(p=0.001)$, and $\mathrm{PI}(p=0.002)$ than the intact group (female $n=10$, male $n=12$, mean age 65.7 \pm 12.4 years). No significant difference was registered between groups in regard of SS, LL, TK, FOA, and the mean number of comorbidities.
\end{abstract}

Conclusion: Failure of restoration of the SVA and the LG to the acceptable ranges, especially in patients with a high PI, may be regarded as a risk factor for the long-term failure of implants after posterior thoracolumbar spinal fusion.

Keywords: Sagittal alignment, Posterior fixation, Failure of the implants, Thoracolumbar spine

\section{Background}

The importance of sagittal alignment in healthy individuals and in reconstructive spinal surgery has been studied over the last 15 years [1-5]. Indeed, the conservation of sagittal alignment is a crucial factor for the ability of the human body to maintain a standing position with minimal energy expenditure [6]. Clinically, the assessment of

\footnotetext{
* Correspondence: josef.grohs@meduniwien.ac.at

'Department of Orthopedics and Trauma Surgery, Division of orthopedics, Medical University of Vienna, Waehringer Guertel 18-20, A-1090 Vienna, Austria

Full list of author information is available at the end of the article
}

sagittal alignment is a mandatory aspect of preoperative planning in order to minimize postoperative complications, including adjacent segment disease and progressive deformity $[5,7]$.

Le Huec et al. reported a significant correlation between a high postoperative PT on the one hand, and postoperative back pain and the risk of adjacent segment degeneration on the other [8].

A high PI and failure to restore a reasonable lumbar lordosis were found to be risk factors for the development of degenerative spondylolisthesis and the failure of

(C) The Author(s). 2020 Open Access This article is licensed under a Creative Commons Attribution 4.0 International License, which permits use, sharing, adaptation, distribution and reproduction in any medium or format, as long as you give appropriate credit to the original author(s) and the source, provide a link to the Creative Commons licence, and indicate if changes were made. The images or other third party material in this article are included in the article's Creative Commons licence, unless indicated otherwise in a credit line to the material. If material is not included in the article's Creative Commons licence and your intended use is not permitted by statutory regulation or exceeds the permitted use, you will need to obtain permission directly from the copyright holder. To view a copy of this licence, visit http://creativecommons.org/licenses/by/4.0/ The Creative Commons Public Domain Dedication waiver (http://creativecommons.org/publicdomain/zero/1.0/) applies to the data made available in this article, unless otherwise stated in a credit line to the data. 
lumbopelvic fixation after long fusions in patients with adult spinal deformities (ASD) [9].

Berjano et al. described an abnormal SVA as a risk factor for the failure of surgery and revision surgery after spinal fusion [10]. Yamada et al. registered an association between the patients' satisfaction after corrective spinal fusion surgery and their SVA at the final follow-up [11]. Furthermore, the PI-LL mismatch (LG) after longsegment fusion surgery, particularly for ASD, was found to be associated with residual postoperative symptoms such as low back pain (LBP), lower extremity pain, and numbness [12]. Numerous studies demonstrated a strong correlation between the improvement of sagittal deviation and clinical outcomes after instrumented fusion for various degenerative lumbar spine diseases [11-17].

The evaluation of sagittal spinal alignment involves the assessment of various parameters such as pelvic incidence (PI), lumbar lordosis (LL), pelvic tilt (PT), sacral slope (SS), lordosis gap (LG), thoracic kyphosis (TK), sagittal vertical axis (SVA), and the femoral obliquity angle (FOA) [1, 18-22].

Despite numerous investigations of the effect of sagittal alignment on the clinical outcome of spinal fusion surgery, we lack data concerning the role of sagittal malalignment in the failure of hardware after posterior fixation of the thoracolumbar spine. We hypothesized an association between sagittal malalignment, metal fatigue, and subsequent failure of implants after posterior thoracolumbar spine fusion.

\section{Methods}

Two cohorts of patients who underwent surgery at one institution were reviewed retrospectively. The investigation was approved by the local ethics committee (approval number 1156/2017).

The revision cohort consisted of all patients who underwent revision surgery due to breakage of the implanted rods and/or screws between 2010 and 2016. The control cohort consisted of consecutive patients who had undergone a fusion at a minimum of three levels in the lumbar and/or thoracolumbar spine, had intact implants at the final follow-up visit, and provided their informed consent to participate in the study. Clinical results in controls were assessed with the Oswestry disability index and the visual analogue scale (VAS).

Patients with concomitant neuromuscular, psychological, or malignant disease, traumatic spinal lesions, infectious spinal disease, or Scheuermann's kyphosis [23] as the indication for surgery, fusion systems other than rods and screws, and patients with a coronal plumb line exceeding $4 \mathrm{~cm}$ were excluded from the study, as the mechanical overload in the coronal plane is independent of sagittal alignment. The aim of the study was to evaluate the effect of sagittal malalignment on the durability of the implants.

Clinical, surgical, and radiographic data obtained from the hospital records were assessed. Standard anteroposterior and lateral radiographs of the full spine in standing position were analysed for each patient.

In the revision cohort, we assessed the preoperative radiographs taken before the index surgery and the radiographs obtained at the time of the patients' presentation in order to define the cause of the symptoms and prepare for potential revision surgery. In the control cohort, the radiographs were obtained at the final follow-up visit.

The following parameters were determined on lateral radiography for each patient: pelvic incidence (PI), lumbar lordosis (LL), pelvic tilt (PT), sacral slope (SS), lordosis gap (LG) or PI-LL mismatch, thoracic kyphosis (TK), sagittal vertical axis (SVA), and the femoral obliquity angle (FOA) [1, 18-22].

In controls, clinical outcomes were assessed at the final follow-up using the ODI and the VAS score for leg and back pain [24].

\section{Statistical analysis}

The SPSS software (IBM SPSS Statistics Version 23) was used for statistical analysis. An unpaired t-test was employed to evaluate mean values of normally distributed data (demographic data, LL, SS, PT, PI, SVA, TK and LG), while the Mann-Whitney $U$ test was used to assess mean values of not normally distributed data (FOA). Pearson's correlation analysis was employed to assess the relationship between radiological parameters and the VAS and ODI scores in the control cohort. A multivariate binary logistic regression analysis (Wald test) was performed to define radiological parameters that could be a risk factor for the breakage of implants.

\section{Results}

Demographics and patients' characteristics are summarized in Table 1.

A review of the patients' medical history revealed that 30 patients in the revision cohort and 18 patients in the

Table 1 Demographics and patient characteristics

\begin{tabular}{llll}
\hline & $\begin{array}{l}\text { Revision cohort } \\
\text { mean } \pm \text { SD }\end{array}$ & $\begin{array}{l}\text { Control cohort } \\
\text { mean } \pm \text { SD }\end{array}$ & p-values \\
\hline Number F/M & $\begin{array}{l}(n=30) \\
M=9 F=21\end{array}$ & $\begin{array}{l}(n=22) \\
M=12 \mathrm{~F}=10\end{array}$ & \\
Age (years) & $62.5 \pm 15.7$ & $65.7 \pm 12.4$ & 0.23 \\
BMl & $26.9 \pm 6.4$ & $26.8 \pm 4.7$ & 0.66 \\
Number of fixed segments & $7.6 \pm 3.6$ & $5.6 \pm 2.4$ & 0.21 \\
Follow-up (years) & $3.6 \pm 2.9$ & $3.8 \pm 1.7$ & 0.9 \\
\hline
\end{tabular}

An independent sample t-test revealed no significant difference between the two cohorts in terms of age, BMl, the number of fixed segments, and the duration of follow-up 
control group had various cardiovascular, respiratory, endocrinal, neurological, osteoporotic, and gastrointestinal diseases. The mean number of comorbidities was $2.4 \pm 1.8$ and $2.3 \pm 1.9$ in the two groups, respectively $(p=0.9)$. In the revision cohort, three patients had ASA1, 17 had ASA2, nine had ASA3, and one patient had ASA4. In the control cohort, three patients had ASA1, 13 had ASA2, four had ASA3, and two patients had ASA4.

The duration of follow-up did not differ significantly between groups $(p=0.9)$.

In the revision cohort, 11 patients presented to the department after failure of the index operation performed at other hospitals, while 19 patients were operated on at our department by two of our surgeons.

The indication for the index operation was correction of scoliosis in 11 patients, while the indication in the remaining patients was spondylochondrosis [25] and instability. The operative techniques used were posterolateral fusion (PLF) with or without transforaminal lumbar interbody fusion (TLIF), Smith-Peterson osteotomy (SPO), or combinations of the two techniques. No pedicle subtraction osteotomy (PSO) was performed in this group. The lower instrumented segment was L5 in five patients and $\mathrm{S} 1$ in the remaining patients. The upper instrumented segments varied from L3 to Th11.

Sagittal parameters measured on full-spine radiographs before the index operation revealed sagittal malalignment that was not corrected by the index operation and did not differ significantly from the sagittal malalignment measured at the time of the patients' presentation with broken rods and/or screws $(p>0.05)$; the data are shown in Table 2.

Breakage sites of screws and/or rods and sites of screw loosening in the revision cohort are listed in Table 3.

Table 2 Radiographic measurements in the revision cohort

\begin{tabular}{|c|c|c|c|}
\hline & First operation & Revision surgery & $p$-values \\
\hline $\begin{array}{l}\mathrm{LL}\left(^{\circ}\right) \\
\text { mean } \pm \mathrm{SD}\end{array}$ & $27.4 \pm 15.7$ & $34.6 \pm 20.3$ & 0.86 \\
\hline $\begin{array}{l}\mathrm{SS}\left({ }^{\circ}\right) \\
\text { mean } \pm \mathrm{SD}\end{array}$ & $29.9 \pm 6.7$ & $34.4 \pm 10.2$ & 0.74 \\
\hline $\begin{array}{l}\mathrm{PT}\left({ }^{\circ}\right) \\
\text { mean } \pm \mathrm{SD}\end{array}$ & $32.6 \pm 7.7$ & $33.3 \pm 9.6$ & 0.95 \\
\hline $\begin{array}{l}\mathrm{PI}\left({ }^{\circ}\right) \\
\text { mean } \pm \mathrm{SD}\end{array}$ & $62.5 \pm 10.7$ & $67.7 \pm 14.7$ & 0.8 \\
\hline $\begin{array}{l}\text { SVA }(\mathrm{mm}) \\
\text { mean } \pm S D\end{array}$ & $104.4 \pm 48.5$ & $112.2 \pm 64.8$ & 0.83 \\
\hline $\begin{array}{l}\mathrm{TK}\left({ }^{\circ}\right) \\
\text { mean } \pm \mathrm{SD}\end{array}$ & $24 \pm 15.3$ & $26.4 \pm 16.7$ & 0.61 \\
\hline $\begin{array}{l}\mathrm{LG}\left({ }^{\circ}\right) \\
\text { mean } \pm \mathrm{SD}\end{array}$ & $24.2 \pm 16.5$ & $33.9 \pm 19.5$ & 0.90 \\
\hline $\begin{array}{l}\text { FOA } \\
\text { Median / IQ range }\end{array}$ & $10 \pm 13$ & $8 \pm 12$ & 0.94 \\
\hline
\end{tabular}

The means of each parameter revealed no significant differences between the first operation and the time of revision surgery
Table 3 Sites of screw breakage, rod breakage, and screw loosening

\begin{tabular}{llll}
\hline $\begin{array}{l}\text { Level of the } \\
\text { problem }\end{array}$ & $\begin{array}{l}\text { Number of screw } \\
\text { breakages }\end{array}$ & $\begin{array}{l}\text { Number of rod } \\
\text { breakages }\end{array}$ & $\begin{array}{l}\text { Number of screw } \\
\text { loosenings }\end{array}$ \\
\hline Th11 & & 3 & \\
Th12 & 1 & 2 & \\
L1 & & 1 & \\
L2 & 1 & & 1 \\
L3 & 1 & 3 & \\
L4 & 2 & 2 & 5 \\
L5 & 4 & 3 & \\
S1 & 4 & 3 & \\
\hline
\end{tabular}

The control cohort consisted of 22 patients who were operated by two surgeons at the department. Three patients had degenerative scoliosis while the remaining patients had spondylochondrosis and instability. The surgical procedure used was PLF with or without TLIF. PSO at the level of L4 was performed in two patients. The lower instrumented segment was L3 and L5 in two patients, and $S 1$ in the remaining patients. The upper instrumented segments varied from L2 to Th11.

Figure 1 shows the number of contacted patients and the numbers excluded from the control group.

Radiological assessment revealed that the anterior shift at $\mathrm{C} 7$ was higher in the revision cohort than in controls (mean SVA values $( \pm$ SD) values $112.2 \pm 64.8$ vs. $67.1 \pm$ 32.6 , respectively, $p=0.02$ ). The PI-LL mismatch (LG) was higher in the revision cohort than in controls (mean LG values $( \pm$ SD) were $33.9 \pm 19.5$ vs. $11 \pm 9.7$, respectively, $p=0.001$ ). Pelvic retroversion was higher in the revision cohort than in controls (mean PT values $( \pm \mathrm{SD}$ ) were $33.3 \pm 9.6$ vs. $23.5 \pm 7.6$, respectively, $p=0.001$ ). However, there was no significant difference in FOA between the two groups. Pelvic incidence was higher in the revision cohort than in controls $(p=0.002)$. However, no statistically significant differences were noted between groups in regard of their mean values of LL, SS, TK, and the AP C7 plumb line $(p>0.05)$. Radiographic measurements are listed in Table 4.

A multivariate binary logistic regression analysis revealed significant differences between the revision group and controls in regard of PT $(p=0.005)$, PI $(p=0.006)$, SVA $(p=$ $0.037)$, and LG ( $p=0.004)$; the data are listed in Table 4 .

Clinical assessment of controls revealed a moderate correlation between SVA and the total ODI score $(r=0.56, p=0.01)$ as well as the VAS score for back pain $(r=0.4, p=0.04)$. In the revision cohort, patients presented with disabling back pain of sudden onset. Radiographs were obtained to determine the cause of pain, and revision surgery was performed. Under these circumstances, pain and disability were not evaluated before surgery. 


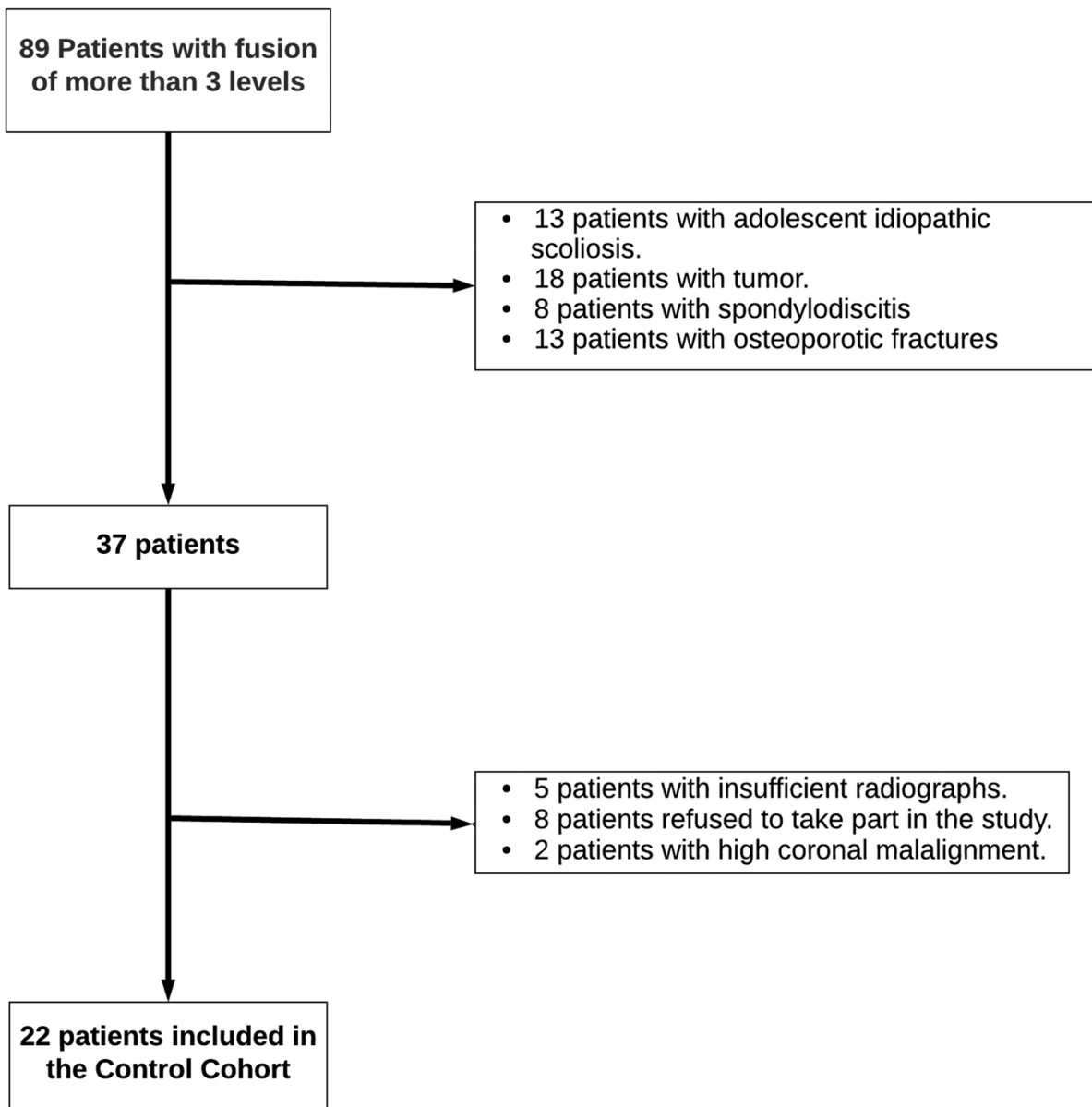

Fig. 1 Flowchart of patients who were requested to be part of the control group

\section{Discussion}

Several studies have reported the debilitating course of sagittal malalignment, which requires enormous energy expenditure to maintain the standing position and subsequently impairs the patient's quality of life [7, 26-28]. However, to the best of our knowledge, this is the first study addressing the effects of postoperative sagittal malalignment on the durability of implants after a long posterior spinal fixation of the lumbar and/or thoracolumbar spine.

Notably, in the present study, the sagittal parameters measured on full-spine radiographs obtained before the index operation revealed sagittal malalignment that was not corrected by the index operation and did not differ

Table 4 Radiographic measurement

\begin{tabular}{|c|c|c|c|c|}
\hline & Revision cohort & Control cohort & $p$-values* & $\begin{array}{l}P \text {-values } \\
\text { Wald test }\end{array}$ \\
\hline $\mathrm{LL}\left(^{\circ}\right)$ mean $\pm \mathrm{SD}$ & $34.6 \pm 20.3$ & $43.4 \pm 14.3$ & 0.15 & 0.366 \\
\hline $\mathrm{SS}\left(^{\circ}\right)$ mean $\pm \mathrm{SD}$ & $34.4 \pm 10.2$ & $30.8 \pm 9.5$ & 0.22 & 0.162 \\
\hline $\mathrm{PT}\left(^{\circ}\right)$ mean $\pm \mathrm{SD}$ & $33.3 \pm 9.6$ & $23.5 \pm 7.6$ & 0.001 & 0.005 \\
\hline $\mathrm{PI}\left({ }^{\circ}\right)$ mean $\pm \mathrm{SD}$ & $67.7 \pm 14.7$ & $54.7 \pm 12.4$ & 0.002 & 0.006 \\
\hline $\mathrm{SVA}(\mathrm{mm})$ mean $\pm \mathrm{SD}$ & $112.2 \pm 64.8$ & $67.1 \pm 32.6$ & 0.02 & 0.037 \\
\hline $\mathrm{TK}\left({ }^{\circ}\right)$ mean $\pm \mathrm{SD}$ & $26.4 \pm 16.7$ & $30.6 \pm 14.7$ & 0.60 & 0.621 \\
\hline$L G\left(^{\circ}\right)$ mean $\pm S D$ & $33.9 \pm 19.5$ & $11 \pm 9.7$ & 0.001 & 0.004 \\
\hline FOA Median / IQ range & $8 \pm 12$ & $6 \pm 6$ & 0.7 & 0.357 \\
\hline
\end{tabular}

${ }^{*}$ The mean values of PI, PT, SVA, and LG were significantly lower in controls than in the revision cohort (independent sample t-test). A multivariate binary logistic regression analysis (Wald test) showed significant differences in PT, PI, SVA, and LG between the revision cohort and controls 
significantly from the sagittal malalignment registered when the patients presented with broken rods and/or screws after a mean follow-up period of $3.6 \pm 2.9$ years. This confirms the presence of sagittal malalignment after the index operation and contradicts the thesis that the broken implants were the reason for sagittal malalignment.

Based on conventional X-rays, Schwab et al. reported the role of PT, PI, and LL combined with SVA in predicting a patient's disability [29]. The authors proposed threshold values for severe impairment (Oswestry disability index $(\mathrm{ODI})>40)$, which included $\mathrm{PT} \geq 22^{\circ}$, SVA $\geq 47 \mathrm{~mm}$, and PI-LL (LG) $\geq 11^{\circ}$ [28]. Moreover, the authors emphasized the significance of restoring a low SVA and PT, and an LL proportional to PI as critical goals when planning realignment surgery for adult spinal deformity [7, 30]. In this context, our control cohort had an abnormally high mean SVA that was manifested clinically as an increase in total ODI and VAS scores. The revision cohort had a much higher SVA compared to controls. Patients in the revision cohort sought medical advice and subsequent surgery because of pain.

In the revision cohort, the second operation was performed on average 3.9 years after the index operation; this interval did not differ from the follow-up period in controls.

PI-LL matching, which was defined in our study as LG, is a vital tool in planning surgery for the correction of sagittal deformity [7], as well as a critical radiological parameter for establishing the clinical outcome [7]. In a prospective multicentre study, Schwab et al. predicted disability (defined as ODI $>40$ ) on the basis of a PI-LL $\geq$ $11^{\circ}$ [28]. However, patients with an abnormal LG and a normal SVA, which is compensated sagittal malalignment, may experience severe disability [31]. Aoki et al. demonstrated the effect of PI-LL mismatch on the persistence of postoperative low back pain, leg pain, and numbness [12]. According to Yamada et al., patients with a postoperative PI-LL mismatch were less satisfied with the surgical outcome [11]. Restoration of lumbar lordosis and correction of PI-LL mismatch prevent sagittal decompensation after long spinal fusion surgery [7]. Failure to restore SVA and LG to the normal range in minimally invasive spinal deformity surgery was associated with poor clinical outcomes [32]. In our study, patients who experienced breakage of their implants had a higher SVA and LG than those without failure of their implants. The higher LG values in the revision cohort indicate that an adequate degree of lordosis was not restored in patients with a higher PI, which may imply that the implants had to sustain higher loads, resulting in metal fatigue.

PT is commonly described as a compensatory mechanism. In the presence of sagittal malalignment, the individual will try to maintain posture by retroversion of the pelvis (an increase of PT); this has a significant impact on the clinical outcome and as well as the patient's satisfaction [7]. A postoperative $\mathrm{PT}<20^{\circ}$ is necessary to obtain an optimal result. The realignment of SVA $<50$ $\mathrm{mm}$ in the presence of a high PT means that the patient is still compensating for a residual structural spinal deformity [7]. Accordingly, several studies reported on the correlation between clinical outcomes and postoperative PT $[8,17,33-36]$. In our investigation, the presence of a high $\mathrm{PT}$ in the revision cohort indicated that the patients' compensatory mechanisms were exhausted. The residual global malalignment was confirmed by a high SVA, which may aggravate stress on the hardware.

PI is a fixed anatomical parameter of primary importance, commonly used to define spinopelvic morphotypes or the required lumbar alignment under optimal conditions $[37,38]$. The restoration of a low sagittal vertical axis and pelvic tilt values when planning realignment surgery for adult spinal deformity should be combined with a proportionate lumbar lordosis and pelvic incidence [37-40]. Woojin et al. reported that a large PI was a risk factor for the failure of lumbopelvic fixation after long construct fusion in adults with a spinal deformity [9]. According to Cho et al., the most significant risk factors for sagittal decompensation (of which an SVA falling anteriorly $>8 \mathrm{~cm}$ was considered the most important) were preoperative sagittal imbalance and a high PI. In this context, the mean PI of patients in our revision cohort was significantly higher than the mean PI of controls. In contrast to patients with a low PI, compensation is significantly limited in patients with a high PI because of full femur extension; the iliofemoral ligament becomes tight in the anterior aspect, thus preventing full verticalisation of the sacrum.

A number of other risk factors have been reported for the failure of fusion. Cho et al. registered a propensity for breakage of materials in patients with comorbidities and a preoperative coronal malalignment [9]. However, in the present study we registered no significant difference in the mean numbers of comorbidities between the two cohorts, implying that comorbidities did not influence the breakage of implants.

The relatively small size of the sample is a potential limitation of the study. Nevertheless, the statistical analysis revealed significant differences between the two groups in regard of various important radiographic parameters. Further biomechanical studies will have to address the role of a high SVA, LG, and PI as risk factors for the breakage of implants.

\section{Conclusion}

Failure to restore the SVA to the acceptable range and the presence of a high LG, especially in patients with a 
high PI, may be regarded as risk factors for the longterm failure of implants after a posterior thoracolumbar spine fusion. These risk factors imply that the failure of surgical restoration of sagittal alignment with subsequent debilitation of compensatory mechanisms may increase stress on the hardware, lead to metal fatigue, and aggravate the risk of rod and/or screw breakage. Additional biomechanical studies will have to assess the importance of these factors.

\section{Acknowledgements}

Not applicable.

\section{Authors' contributions}

JGG conceived and designed the study. ME wrote the manuscript with contributions by JGG, ST, and WH. ME and JGG performed the radiographic measurements and assessed clinical outcomes. ME, JGG, and ST performed the statistical analysis. All authors analysed and interpreted the data. All authors discussed, revised, and approved the final manuscript.

\section{Funding}

Not applicable.

\section{Availability of data and materials}

The datasets used and/or analysed for the current study can be provided by the corresponding author on reasonable request

\section{Ethics approval and consent to participate}

A positive vote of the ethics committee of the Medical University of Vienna, Austria, was obtained for the study (ethics committee approval number: 1156/2017).

\section{Consent for publication}

Not applicable.

\section{Competing interests}

The authors declare that they have no competing interests.

\section{Author details}

'Department of Orthopedics and Trauma Surgery, Division of orthopedics, Medical University of Vienna, Waehringer Guertel 18-20, A-1090 Vienna, Austria. ${ }^{2}$ Karl Chiari Lab for Orthopedic Biology, Department of Orthopedics and Trauma Surgery, Medical University of Vienna, Waehringer Guertel 18-20, A-1090 Vienna, Austria. ${ }^{3}$ Ludwig Boltzmann Cluster for Arthritis and Rehabilitation, Vienna, Austria.

Received: 14 October 2019 Accepted: 4 June 2020

\section{Published online: 16 June 2020}

\section{References}

1. O'Shaughnessy BA, Ondra SL. Measuring, preserving, and restoring sagittal spinal balance. Neurosurg Clin N Am. 2007;18:347-56.

2. Vedantam R, Lenke LG, Keeney JA, Bridwell KH. Comparison of standing sagittal spinal alignment in asymptomatic adolescents and adults. Spine 1998:23:211-5

3. Roussouly P, Transfeldt E, Schwender J, Bethonnaud E, Dimnet J. Sagittal morphology and equilibrium of pelvis and spine in normals. Spine J. 2002;2: 61-2.

4. Le Huec JC, Hasegawa K. Normative values for the spine shape parameters using 3D standing analysis from a database of 268 asymptomatic Caucasian and Japanese subjects. Eur Spine J. 2016:25:3630-7.

5. Vialle R, et al. Radiographic analysis of the sagittal alignment and balance of the spine in asymptomatic subjects. J Bone Joint Surg. 2005;87:260-7.

6. French National Academy of Medicine, Dubousset J. 3D analysis of scoliotic deformity development and 3D chain of balance in a scoliosis patient. Hirurgiâ Pozvonočnika. 2016;13:108-13.

7. Schwab F, Patel A, Ungar B, Farcy J-P, Lafage V. Adult spinal deformity_postoperative standing imbalance. Spine. 2010;35:2224-31.
8. Le Huec JC, Faundez A, Dominguez D, Hoffmeyer P, Aunoble S. Evidence showing the relationship between sagittal balance and clinical outcomes in surgical treatment of degenerative spinal diseases: a literature review. Int Orthop (SICOT). 2014;39:87-95.

9. Cho W, et al. Failure of lumbopelvic fixation after long construct fusions in patients with adult spinal deformity: clinical and radiographic risk factors. J Neurosurg Spine. 2013;19:445-53.

10. Berjano $P$, et al. Failures and revisions in surgery for sagittal imbalance: analysis of factors influencing failure. Eur Spine J. 2013;22:853-8.

11. Yamada K, Abe Y, Yanagibashi Y, Hyakumachi T, Satoh S. Mid- and longterm clinical outcomes of corrective fusion surgery which did not achieve sufficient pelvic incidence minus lumbar lordosis value for adult spinal deformity. Scoliosis. 2015;10:1082

12. Aoki $Y$, et al. Influence of pelvic incidence-lumbar lordosis mismatch on surgical outcomes of short-segment transforaminal lumbar interbody fusion. BMC Musculoskelet Disord. 2015;16:343.

13. Korovessis $P$, Repantis T, Papazisis Z, lliopoulos P. Effect of sagittal spinal balance, levels of posterior instrumentation, and length of follow-up on low Back pain in patients undergoing posterior decompression and instrumented fusion for degenerative lumbar spine disease. Spine. 2010;35:898-905.

14. Cho K-J, et al. Risk factors of sagittal Decompensation after long posterior instrumentation and fusion for degenerative lumbar scoliosis. Spine. 2010; 35:1595-601.

15. Videbaek TS, Bünger CE, Henriksen M, Egund N, Christensen FB. Sagittal spinal balance after lumbar spinal fusion. Spine. 2010;1. https://doi.org/10. 1097/BRS.0b013e3181cd9ee5.

16. Kim JS, Kim SM. Surgical outcomes of post-fusion lumbar Flatback deformity with sagittal imbalance. J Korean Neurosurg Soc. 2016;59:615.

17. Faldini $C$, et al. Long vs. short fusions for adult lumbar degenerative scoliosis: does balance matters? Eur Spine J. 2015;24:887-92.

18. Mac-Thiong J-M, Roussouly P, Berthonnaud É, Guigui P. Sagittal parameters of global spinal balance. Spine. 2010;35:E1193-8.

19. Berthonnaud É, Dimnet JS, Roussouly P, Labelle H. Analysis of the sagittal balance of the spine and pelvis using shape and orientation parameters. J Spinal Disord Tech. 2005;18:40-7.

20. Boulay $C$, et al. Sagittal alignment of spine and pelvis regulated by pelvic incidence: standard values and prediction of lordosis. Eur Spine J. 2005;15:415-22.

21. Kosugi Y, Suzuki H. Affinity chromatography of lipase with hydrophobic ligands coupled to cyanogen bromide-activated agarose. J Lipid Res. 1976;17:307-13.

22. Gelb DE, Lenke LG, Bridwell KH, Blanke K, McEnery KW. An analysis of sagittal spinal alignment in 100 asymptomatic middle and older aged volunteers. SPINE. 1995:20:1351-8.

23. Polly DW, et al. What are the indications for spinal fusion surgery in Scheuermann kyphosis? J Pediatr Orthop. 2019;39:217-21.

24. Fairbank JCT. Oswestry disability index. J Neurosurg Spine. 2014;20:239-41.

25. Fardon DF. Nomenclature and classification of lumbar disc pathology. Spine. 2001:26:461-2.

26. Schwab F, et al. Surgical rates and operative outcome analysis in thoracolumbar and lumbar major adult scoliosis: application of the new adult deformity classification. Spine. 2007;32:2723-30.

27. Liu S, et al. Likelihood of reaching minimal clinically important difference in adult spinal deformity: a comparison of operative and nonoperative treatment. Ochsner J. 2014:14:67-77.

28. Schwab FJ, et al. Radiographical Spinopelvic parameters and disability in the setting of adult spinal deformity. Spine. 2013;38:E803-12.

29. Hasegawa K, et al. Normative values of spino-pelvic sagittal alignment, balance, age, and health-related quality of life in a cohort of healthy adult subjects. Eur Spine J. 2016;25:3675-86.

30. Diebo BG, Varghese JJ, Lafage R, Schwab FJ, Lafage V. Sagittal alignment of the spine: what do you need to know? Clin Neurol Neurosurg. 2015;139: 295-301.

31. Smith JS, et al. Surgical treatment of pathological loss of lumbar lordosis (flatback) in patients with normal sagittal vertical axis achieves similar clinical improvement as surgical treatment of elevated sagittal vertical axis. J Neurosurg Spine. 2014;21:160-70.

32. Than KD, et al. Clinical and radiographic parameters associated with best versus worst clinical outcomes in minimally invasive spinal deformity surgery. J Neurosurg Spine. 2016;25:21-5.

33. Roussouly P, Gollogly $\mathrm{S}$, et al. The vertical projection of the sum of the ground reactive forces of a standing patient is not the same as the C7 plumb line. Spine. 2006;31:E320-5. 
34. Vaz G, Roussouly P, Berthonnaud E, Dimnet J. Sagittal morphology and equilibrium of pelvis and spine. Eur Spine J. 2002;11:80-7.

35. Lafage V, Schwab F, Patel A, Hawkinson N, Farcy J-P. Pelvic tilt and Truncal inclination. Spine. 2009;34:E599-606.

36. Barrey C, Jund J, Noseda O, Roussouly P. Sagittal balance of the pelvis-spine complex and lumbar degenerative diseases. A comparative study about 85 cases. Eur Spine J. 2007;16:1459-67.

37. Hiok A, Miyamoto K, et. al. Lumbar axial loading device alters lumbar sagittal alignment differently from upright standing position. Spine. 2010;35: 995-1001.

38. Schwab F, Patel A, Ungar B, Farcy J-P, Lafage V. Adult spinal deformitypostoperative standing imbalance: how much can you tolerate? An overview of key parameters in assessing alignment and planning corrective surgery. Spine. 2010;35:2224-31.

39. Koller $\mathrm{H}$, et al. Factors influencing radiographic and clinical outcomes in adult scoliosis surgery: a study of 448 European patients. Eur Spine J. 2015, 25:532-48.

40. Rose PS, Bridwell KH, Lenke LG, et al. Role of pelvic incidence, thoracic kyphosis, and patient factors on sagittal plane correction following pedicle subtraction osteotomy. Spine. 2009;34(8):785-91.

\section{Publisher's Note}

Springer Nature remains neutral with regard to jurisdictional claims in published maps and institutional affiliations.

Ready to submit your research? Choose BMC and benefit from:

- fast, convenient online submission

- thorough peer review by experienced researchers in your field

- rapid publication on acceptance

- support for research data, including large and complex data types

- gold Open Access which fosters wider collaboration and increased citations

- maximum visibility for your research: over $100 \mathrm{M}$ website views per year

At BMC, research is always in progress.

Learn more biomedcentral.com/submissions 